plastic deformations was made by dealing with single-bay rectangular portal frames; the lateral instability of steel beams bent until they had partially yielded was studied, and a considerable programme of tests on battened struts was carried out.

In addition to these investigations under static loading conditions, attention has been given to the fatigue strength of structures. Equipment was developed successfully for carrying out fatigue tests on full-scale structures and structural components by the resonance vibration method.

A comprehensive investigation into the behaviour of light alloy struts was made, and an experimental and theoretical study of the lateral instability of light alloy beams is also being undertaken with the help of the Aluminium Development Association.

\section{RABELAIS ON SYPHILIS}

$I^{\mathrm{N}}$ a thesis for a doctorate in medicine at the University of Paris, Dr. Mottron has chosen to extract from the books of Gargantua and Pantagruel all the references to syphilis ("Rabelais et la Verole". By J. Mottron. Pp. 127. Tours: Arrault et Cie., 1947). The texts are quoted in extenso and the commentary thereon gives a study of syphilis as it was understood in the first half of the sixteenth century.

Rabelais was a contemporary of Fracastorius, but he did not use the term syphilis, which only became popular much later. In the prologue to Gargantua, Rabelais dedicates his writings to "Buveurs tresillustres, et vous verolez tresprecieux". His references to the disease are all in terms that could be understood by his lay readers.

The epidemic of syphilis in Europe began in 1493, and when Rabelais was writing there was already a good descriptive knowledge of the disease. The chancre was recognized as the primary focus of infection and its characteristic induration had been described. Also known were the short latent period before the start of the secondary stage with its crousteleves, or rupial lesions, and all the other manifestations of secondary syphilis on the skin and in the nervous system.

It was fortunate that mercury, the only useful remedy of the times, was used almost at once, and by accident, in the treatment of the new disease and that its good effects were recognized. Mercury was first used by inunction, and there is an allusion to this method of treatment in Rabelais' prologue to the books of Pantagruel. The toxic effects of mercury are also mentioned. When mercury was shown to affect syphilis the dosage was increased to toxic levels, and the ill-effects were confused with the manifestations of the disease itself. This confusion resulted in the change to guaiacum which, for a short period, superseded mercury.

Although mercury was used orally as early as 1533, inunction long continued as the chief mode of application. Sweating baths were often associated with mercury inunctions. Gasparo Torrella (1497) recommends the "best way to treat syphilis is to sweat the patient for fifteen days, fasting, in a steam bath or oven". Jean Fernel (1557) writes of steam baths at high temperature for twenty days or more. Sarsaparilla, a sudorific agent used in conjunction with baths, is also mentioned by Rabelais. The vogue for sweating has continued ever since. Baths in mercury vapour were used by Langston Parker in 1850 and to-day we use more elaborate methods in the hypertherms. Rabelais seems to have intended his works to be read by the suffering verolez while they were sweating. It is doubtful whether even Rabelais could mitigate the sufferings of the modern sweating cabinet; but it is an idea which ought to be tried.

Dr. Mottron seems to favour the theory that syphilis existed in Europe in the pre-Columbian era and that the disease was unrecognized before 1493 , or confused with leprosy, scabies, etc. He cites Broca's (1876) observation of the discovery of syphilitic lesions in bones from an ancient leprosorium, and quotes the monk Theodoric (thirteenth century), Gaddesden (fourteenth century) and Bernard Gordon (1305) on the transmission of 'leprosy' by sexual intercourse.

The evidence of contemporary observers such as Torrella and Ulrich von Hütten is, however, of a new, hitherto unknown disease which alarmed the doctors to the point where they fled from the presence of the sick. Public health measures were quickly enacted all over Europe. In Paris, in 1497, foreigners with the great pox were warned to leave the city under pain of the halter for disobedience, and eitizens so affected had to stay always indoors. The next year, 1498, the penalty for the unfortunate syphilitic discovered at large in Paris was to be thrown into the river. In the city of Aberdeen, at the same time, to combat the French disease, it was ordained "that all licht weman be chargit and ordanit to decist fra their vicis and syne of venerie, and all their bothis and housais skalit". All these evidences suggest something absolutely new and terrifying.

In favour of the American origin for syphilis are many points unspecified by Dr. Mottron. He does not mention, for example, Ruy Diaz de Isla's "Tractado Contra el Mal Serpentina", in which is described the treatment, at Barcelona, of some of Columbus's men on their return from Haiti. Nor does he allude to more recent investigations on ancient bones which seem to show that syphilitic osteitis did not occur in Europe or Egypt before the sixteenth century. This controversy is, however, interminable and can be closed for the present with the observation that Rabelais talks of a case of the verole in 1420 .

The entity of syphilis is recognized by Rabelais. He mentions gonorrhcea only rarely, but it is quite clear that he knew it as a separate disease. Syphilis was also distinguished from leprosy in Rabelais' day. Vibert speaks of lepers fearing contamination from syphilitics. Rabelais knew syphilis to be a contagious and venereal disease; but he does not seek, like some of his contemporaries, for causes in planetary disturbances, poisoned water, cannibalism, etc.

Dr. Mottron ascribes to Rabelais the tract "Triomphe de Très Haute et Puissante Dame Vérole". In this is cited, perhaps for the first time, a cause for venereal disease which is still occasionally suggested by patients :

\section{"Et notre fiffre a uriné \\ Contre un mur dont mal lui en print".}

Dr. Mottron is to be congratulated on his scholarly development of a very interesting theme. My only criticism is of his rather one-sided treatment of the theory of the American origin of syphilis; but as Rabelais is on his side I shall say no more. James MarshalL 